\title{
Interactions between Autonomic Nerves and Endocrine Cells of the Gastroenteropancreatic System*
}

\author{
P. H. Smith and Katherine L. Madson ${ }^{1}$ \\ Department of Anatomy, Upstate Medical Center, State University of New York, Syracuse, New York, USA
}

Summary. Autonomic nerves and endocrine cells of both the gastrointestinal tract and the pancreatic islets participate in the control of several processes related to the digestion and metabolism of nutrients. While it was once thought that they acted separately to regulate these processes, it is now appreciated that numerous interactions exist between the functions of autonomic nerves and GEP endocrine cells. Recent studies show that autonomic signals play a role in the secretory activity of various GEP cells, thus providing a mechanism by which the central nervous system can integrate digestive and metabolic functions. It also has been shown that nerves and endocrine cells frequently share certain common peptides and/or amines. Therefore, in functional terms, it is often difficult to determine whether a specific peptide or amine should be considered a neurotransmitter or a hormone. Within the next few years, one can reasonably expect that new techniques and methods of investigation will clarify the roles of putative chemical messengers such as the peptides found within autonomic nerves and the amines found within endocrine cells. It also seems likely that future studies will demonstrate that the specific chemical messenger and the mechanism by which it reaches its target cells are far more important factors in the understanding of gastrointestinal and endocrine pancreatic function, than whether or not these signals are neural or endocrine in origin.

Key words: Autonomic nervous system, GEP system, enteric nervous system, peptidergic neurons, paracrine, neurocrine

\footnotetext{
Supported in part by NIH grant AM-25325

1 Postdoctoral Fellow of the Juvenile Diabetes Foundation
}

Not long ago it was possible to define the nervous system and the endocrine system as separate entities. Today, however, the distinction between these two systems is less clear. This is due to an increasing number of studies which show that central and peripheral nerves often contain peptides formerly thought to be solely within the domain of the endocrine system $[5,25,33,39,46]$. Likewise, certain endocrine cells have been shown to contain substances once considered unique to neural tissue [5, $30,33,60]$. In fact, the problem of defining these two systems becomes particularly acute when attempting to separate the respective roles of nerves and endocrine cells in complex processes such as the regulation of gastrointestinal and pancreatic islet functions. In this paper we shall attempt to provide an overview of several of the interactions that exist between the autonomic nervous system and the gastroenteropancreatic (GEP) endocrine system. To accomplish this task the structure of each of these systems will be examined and then correlations will be drawn concerning their functional interrelationships. Because our coverage of this topic is necessarily limited, a concerted effort has been made to point out recent studies and more comprehensive reviews of this field.

\section{Endocrine Cells of the GEP System}

The GEP endocrine cells comprise some 15 to 18 $[33,46]$ peptide-containing cells located in either the gastrointestinal tract or pancreatic islets (see Table 1). It is thought that all of these cells share a common embryological origin. However, there are currently two rather differing theories as to their exact origin. Adherents of the more traditional view hold that all of these cells are derived from the endoderm, and that stem cells of this germ-layer con- 

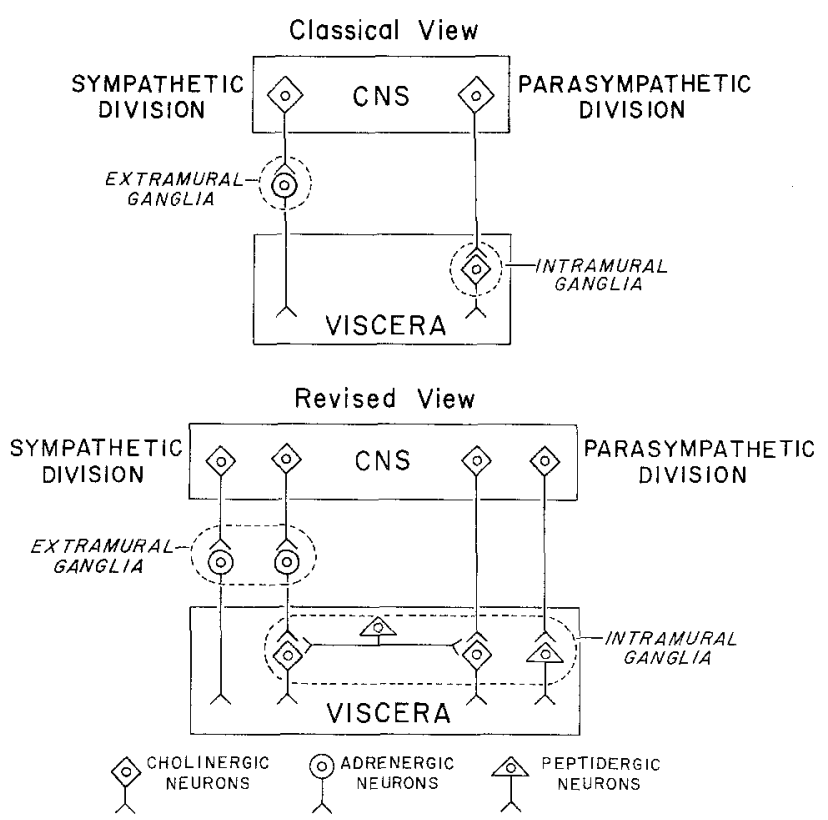

Fig. 1. The classical and revised views of the autonomic nervous system. The classical view provided for the inhibition or stimulation of visceral function by the sympathetic or parasympathetic nerves, respectively. Afferent fibers to the CNS, and many of the interactions between sympathetic, parasympathetic and enteric neurons were unknown when Langely proposed his original concept. A revised view of this basic scheme is presented based on newer data showing that all of these nerves interact in the control of gastrointestinal and pancreatic functions. The afferent fibers found in autonomic nerves are not shown. Peptidergic (and possibly purinergic) neurons act as stimulators or inhibitors depending on whether they are pre- or post-synaptically related to other neurons

tribute to the formation of all four types of epithelial cells of the gastrointestinal tract [13] plus the exocrine and endocrine cells of the pancreas [48]. On the other hand, Pearse and his coworkers (for review see [46]), have suggested that the GEP endocrine cells are derived from precursor cells that migrate from the neuroectoderm during embryological development and subsequently colonize the gut. As the pancreas develops from the primitive gut, these cells are carried along to differentiate ultimately into the endocrine cells of the pancreatic islets. The basic observation forming the backbone of this theory is that all of these endocrine cells share with certain neural tissues the capacity of $a$ mine precursor $u$ ptake and decarboxylation. Thus, these cells have been classified as members of the APUD system [46]. Some APUD cells, such as those of the adrenal medulla and neurons of sympathetic ganglia, are known to be derived from part of the neuroectoderm called the neural crest [46]. However, recent experiments, using techniques of neural crest transplantation [20] or ablation [47], have shown that GEP endocrine cells can form independently of this part of the neuroectoderm. Nevertheless, these findings do not preclude the interesting possibility that cells preprogrammed to become GEP endocrine cells might migrate from the neuroectoderm at some time prior to the formation of a definitive neural crest [46].

Regardless of their definitive origin(s), the GEP endocrine cells share many structural and cytochemical features. The endocrine cells of the gastrointestinal tract are found singly, or sometimes in small groups, dispersed among the other epithelial cells of the mucosa. Usually these GEP cells are situated at or near the base of the intestinal glands. Two distinct morphological sub-groups have been identified by Fujita and his colleagues [24] and are termed "open-" or "closed-type" cells. The "open-type" cells display secretory granules that are frequently, but not always, located in the basal part of the cytoplasm and orientated toward the vasculature. The apical portion of these cells extends to the glandular lumen and usually exhibits a microvillous border. The "closed-type" cells lack an apical extension and are thus isolated from the lumen of the gastrointestinal tract. However, these cells also contain numerous secretory granules orientated toward the vascular supply. The endocrine cells of the pancreas form clusters of up to several hundred cells which are dispersed throughout the exocrine tissue. Depending on the particular species there is a definite arrangement of the different types of hormone-containing cells within the islets. The cells of the islet are arranged in irregular cords between extensive capillary loops. Because the islet cells have no particular shape and their secretory granules are always polarized toward capillaries, they closely resemble the "closed-type" endocrine cells of the gastrointestinal tract. When examined by electron microscopy [54], it is often difficult to distinguish the secretory granules of certain islet cells from those of specific endocrine cells in the gastrointestinal tract. Moreover, certain islet and gastrointestinal endocrine cells display similar staining characteristics with metachromatic dyes and/or silver containing solutions [24]. These ultrastructural and tinctorial characteristics are not surprising in view of the many recent studies showing that several hormone-like immunoreactive substances have been localized to endocrine cells of both the gut and the islet.

\section{Autonomic Nerves of the GEP System}

The autonomic nervous system can be divided into three parts: the sympathetic, the parasympathetic, and the enteric (or intrinsic) divisions. The first two 
divisions consist of nerves supplied to an organ by the $\mathrm{CNS}$, whereas the enteric division represents neurons found within an organ. The gastrointestinal tract and pancreas conform to this scheme, since both receive an abundant supply of extrinsic autonomic nerves and contain intrinsic neurons as well.

According to Langley [38], who originated this tripartite view of the autonomic nervous system in 1921 , sympathetic nerves provide tonic inhibitory signals to the viscera, whereas parasympathetic nerves mediate stimulatory signals by their association with the enteric ganglia (Fig. 1). This view, although partially correct in terms of current knowledge, makes no provision for either afferent fibers or the existence of several neurotransmitters. In the past several years, Langley's concept of autonomic nerves has been revised several times (Fig. 1). It is now known, for example, that the sympathetic and parasympathetic nerves both contain numerous afferent fibers $[25,27]$. Further, there is now considerable information showing not only the interplay between sympathetic and parasympathetic nerves with the enteric neurons $[12,66]$ but also the existence of several putative neurotransmitters in addition to norepinephrine and acetylcholine [5, 12, 25, 33, 46].

Extrinsic autonomic fibers reach the gastrointestinal tract from three principal sources: branches from the vagus, branches from the splanchnic nerves (and associated abdominal plexuses), and branches from the pelvic plexus. To a greater or lesser extent, each of these pathways provides both parasympathetic and sympathetic axons, and each contains afferent fibers (for a comprehensive review of these pathways see [27]).

The extrinsic nerves to the pancreas enter the organ in association with its blood supply [36]. These nerves originate from the celiac and superior mesenteric plexuses and contain fibers from the vagal trunks and the splanchnic nerves. In addition to these efferent axons, numerous pancreatic afferent fibers reach the brain and spinal cord via the vagal and splanchnic nerves, respectively $[59,62,67]$.

Unlike the extrinsic autonomic nerves which are under the direct control of the CNS, the intrinsic nerves of the gastrointestinal tract (and possibly those of the pancreas) are known to act independently of CNS signals [25]. The ability of enteric neurons in the gastrointestinal tract to act autonomously is undoubtedly related to their numbers and the complexity of the plexuses that they form. [References [25] and [27] provide excellent, comprehensive reviews of the anatomy of the gastrointestinal enteric nerves.] In the gastrointestinal tract of mammals there are basically two major ganglionated plexuses that extend from the esophagus to the internal anal sphincter. The myenteric, or Auberbach's, plexus is located between the outer longitudinal and inner circular layers of smooth muscle comprising the muscularis externa. A second ganglionated plexus, commonly referred to as Meissner's plexus, lies within the submucosa. These two plexuses are interconnected, and send or receive fibers to or from the different layers of the gut wall. Extrinsic sympathetic axons are associated with these two plexuses, and also innervate the muscular and vascular tissues. The exact distribution of the parasympathetic axons to the two major plexuses and the various muscle layers of the gut is still unknown due to the difficulty of precisely identifying this type of fiber. Despite the numerous sympathetic and parasympathetic axons reaching the gut, most authorities agree $[25,27]$ that these extrinsic fibers comprise a quantitatively small part of the total nerves present in the gastrointestinal tract.

Cytochemical and electron microscopic investigations show the presence of at least 10 distinct types of nerves within the gut $[25,27]$. Only four of them will be discussed in this paper. The first of these nerves is considered to be cholinergic, based on the ultrastructure of its axon terminals. That is, these terminals contain rounded, agranular synpatic vesicles with a diameter of 30-60 nm. These axon terminals are typical of known cholinergic terminals found in areas such as motor-end-plates [25, 27]. Presumably, the cholinergic terminals seen within the gut represent the endings of intrinsic neurons and, to some extent, the endings of the preganglionic parasympathetic fibers. It is also possible that some of these terminals correspond to the presumed serotonergic enteric neurons [27], since terminals of the CNS which are thought to contain serotonin also display this type of ultrastructure [44].

The second type of nerve terminal corresponds, with some certainty, to noradrenergic, postganglionic sympathetic nerves. These endings have been shown to fluoresce following treatment by the Falck-Hillarp technique [17]. They also contain the enzyme dopamine $\beta$-hydroxylase [25], which is necessary for the synthesis of catecholamines. Also, the majority of these terminals disappear after sectioning of the extrinsic nerves. When examined by electron microscopy, terminals of the noradrenergic nerves have been found to contain a population of flattened $(\sim 20 \times 60 \mathrm{~nm})$, dense-cored synaptic vesicles, in addition to the rounded agranular vesicles [25]. It is important to note that there is a third type of ending that exhibits some of the characteristics of the noradrenergic terminals. This third type of ending belongs to the amine-handling neurons. Terminals of these nerves display ultrastructural features that are 
Table 1. Peptides of the gastroenteropancreatic system

\begin{tabular}{|c|c|c|}
\hline Peptide & Cell type & Location \\
\hline Bombesin $^{a, c}$ & $\mathrm{D}_{1}(\mathrm{P})$ & intestine \\
\hline Cholecystokinin $^{\mathrm{a}, \mathrm{c}}$ & $\mathrm{I} / \mathrm{A}$ & intestine/islet \\
\hline$\beta$-Endorphin ${ }^{c}$ & A & islet \\
\hline Enkephalin $^{\mathrm{a}, \mathrm{c}}$ & Nerve & intestine \\
\hline Gastrin $^{a, c}$ & $\mathrm{G}$ & stomach/islet \\
\hline $\begin{array}{l}\text { Gastric inhibitory } \\
\text { polypeptide }\end{array}$ & $\mathrm{K} / \mathrm{A}$ & intestine/islet \\
\hline Glicentin $^{\mathrm{a}, c} \mathrm{c}$ & $\mathrm{L} / \mathrm{A}$ & intestine/islet \\
\hline Glucagon & $\mathrm{A} / \mathrm{AL}$ & islet/stomach \\
\hline Insulin ${ }^{\mathrm{c}}$ & $\mathrm{B}$ & islet \\
\hline Motilin $^{c}$ & $\mathrm{EC}_{2}(\mathrm{M})$ & intestine \\
\hline Neurotensin ${ }^{a}, c$ & $\mathrm{~N}$ & intestine \\
\hline Pancreatic polypeptide $^{\mathrm{a}, \mathrm{c}}$ & $\mathrm{F}$ & islet/intestine \\
\hline Secretion & $\mathrm{S}$ & intestine \\
\hline Somatostatin ${ }^{\mathrm{a}, \mathrm{c}}$ & $\mathrm{D}$ & $\begin{array}{l}\text { islet/intestine/ } \\
\text { stomach }\end{array}$ \\
\hline Substance $P^{a, c}$ & $\mathrm{EC}_{1}$ & intestine/stomach \\
\hline $\begin{array}{l}\text { Vasoactive intestinal } \\
\text { polypeptide } \mathrm{a}, \mathrm{b}, \mathrm{c}\end{array}$ & $\mathrm{H}$ & intestine \\
\hline
\end{tabular}

a found in intestinal nerves; $b$ found in islet nerves; ${ }^{c}$ found in the brain. Cell types classified according to the Lausanne 1977 system for naming gastroenteropancreatic endocrine cells (see [5, $33,46])$

remarkably similar to those of the noradrenergic extrinsic nerves. Further, they are capable of trapping catecholamines and indoleamines causing these nerve to fluoresce when examined by the Falck-Hillarp method. Since the fluorescence of these nerves persists after sectioning of the extrinsic nerves, it has been established that the amine-handling neurons are intrinsic to the gut [25]. That these neurons are amine-handling but not capable of catecholamine synthesis is supported by investigations $[25,26]$ showing that enzymes such as dopamine $\beta$-hydroxylase and tyrosine hydroxylase are absent in denervated segments of the gut.

The fourth type of axon terminals differs significantly from the others in both their cytochemical and ultrastructural characteristics. These nerve endings contain a few of the small, agranular vesicles and many large, secretory granule-like vesicles $80-200 \mathrm{~nm}$ in diameter. Baumgarten et al. [1] have termed such endings "p-type" terminals, and have suggested that they contain peptides. Other studies which show that ATP may act as a transmitter from enteric neurons have prompted Burnstock $[11,12]$ to term such endings "purinergic." However, as discussed in the next section of this paper, numerous peptides have been localized to nerves of the gastrointestinal tract implying that some peptides formerly thought of only as hormones may, in fact, also act as neurotransmitters. For this reason, nerve endings containing the large, granule-like vesicles are frequently termed "peptidergic" $[6,25,27,33,46]$.

The nerves and nerve endings within the pancreatic islets are far less complex than those found in the gastrointestinal tract. Typical cholinergic and adrenergic endings have been observed in the islets $[59,62,67]$, and they conform ultrastructurally and cytochemically to the same types of endings discussed above. However, unlike the terminals observed in the gut, nerve endings within the islets do not form synapses but instead end blindly $20-30 \mathrm{~nm}$ from the endocrine cells. There is no preferential distribution of a given type of nerve terminal to a specific population of islet cells. Thus it would seem that neurotransmitters released from these nerve endings may simply diffuse throughout the extracellular space of the islet, possibly affecting several types of endocrine cells stimultaneously.

Presumably, the majority of nerve endings observed in the endocrine pancreas correspond to the terminals of extrinsic neurons, since intrinsic neurons of the islets seem to be relatively sparce in comparison to those of the gut. Nevertheless, nerve cell bodies are present in the islets of both fetal and postnatal animals $[8,37,48]$. As pointed out by Fujita [23], there are two general types of complexes consisting of either a juxtaposition of islet cells and nerve cells, or the more frequently observed association of islet cells and nerve fibers.

\section{Peptides and Amines of the GEP Neuroendocrine System}

Table 1 lists several "peptide-like" immunoreactive substances that, to date, have been localized to nerves and/or endocrine cells of the GEP system ${ }^{2}$. Considering the rapidity with which new (or unexpected) peptides are reported to be present within these tissues it is likely that this is only a partial representation of the complete list. Since the function of the various gastrointestinal hormones, or candidate hormones, is the subject of several excellent reviews $[4,5,30,45,50]$, we shall concentrate here on only

\footnotetext{
2 An extremely important issue when considering the identity of a peptide-like material is that immunocytochemical methods show the presence of immunoreactive substances not necessarily corresponding to the peptide used to generate a certain "species" of antibodies. That is, any given antiserum may contain sub-populations of antibodies capable of cross-reacting with numerous closely related peptides. Thus, as techniques improve, our current concepts of the presence of specific peptides in nerves or endocrine cells may require rather drastic revisions
} 
the potential roles of the peptides found in GEP nerves.

There is now ample evidence that the functional role of some of these neuropeptides is associated with the morphology and distribution of the neurons which contain them [25, 27]. For example, substance $\mathrm{P}$ and vasoactive intestinal polypeptide (VIP) are two peptides found in axons distributed primarily to the muscles of the gut wall. Several investigations have provided evidence supporting the concept that substance $\mathrm{P}$ and VIP correspond, respectively, to the non-cholinergic excitatory $[21,22,25]$ and nonadrenergic inhibitory $[7,25]$ transmitter-like substances released by intrinsic neurons. Axons containing VIP are also distributed to the smooth muscle of the intestinal vasculature and there is strong evidence that this peptide plays an important role in vasodilation $[7,51]$. On the other hand, somatostatin-containing intrinsic neurons send their axons mainly to the ganglionated plexuses $[25,27]$. Since somatostatin has little direct effect on intestinal smooth muscle [25], it is thought that the neurons containing this peptide represent interneurons whose function is to decrease the rate of acteylcholine release and/or to stimulate the activity of intrinsic inhibitory neurons $[14,31]$. Neurons containing leu- or met-enkephalin represent nerves displaying a type of distribution intermediate to the other peptide-containing nerves discussed above. Axons of these neurons are found mainly in the myenteric plexus, but they also supply the smooth muscle of the muscularis externa. Cell bodies of these neurons are predominantly in the myenteric plexus and rarely are found in the submucosal plexus $[16,32]$. There is evidence that these neurons decrease muscular contraction not only by a direct effect but also by inhibiting the release of acetylcholine from the intrinsic excitatory nerves whose cell bodies are located in the myenteric plexus [25]. Only limited information [25, 27] is currently available concerning the physiological and/or pharmachological action of the other peptide-like immunoreactive substances listed in Table 1. Thus an understanding of their roles in gastrointestinal functions must await further studies.

Peptides also have been localized to fine, varicose nerve fibers in the pancreas of several species. Fibers containing VIP are found in close association with the endocrine pancreas where they form a peri-insular nerve network $[3,61]$. Frequently, these fibers are in close proximity to, or terminate on, the endocrine cells of the islet [3]. Substance P-containing nerve fibers have been observed in the pancreas of adult rats. However, this latter type of "peptidergic" nerve was reported to be mainly associated with the exocrine pancreatic tissue [39]. As discussed below, there is now evidence that several of these neurallyrelated peptides play a role in the regulation of pancreatic islet function.

In addition to the classical neurotransmitters such as acetylcholine or norepinephrine, several other amines have been found in GEP nerves and/or endocrine cells. Serotonin is present in the enterochromaffin cells of the gastrointestinal mucosa, and in certain enteric nerves where it presumably acts as a typical transmitter substance $[25,27]$. Depending on the species, histamine and melatonin also may be present in the enterochromaffin cells [46]. These latter substances, however, probably do not play a role as neurotransmitters in gastrointestinal function, but nevertheless may exert other physiological actions. The pancreatic islet cells of many species contain serotonin and/or dopamine $[18,40,41]$. In general, these amines act as inhibitors of islet hormone secretion. However, through interactions with the transmitters of intraislets nerves it is possible for them also to act as stimulators of islet function (see $[59,60]$ ).

\section{The Control of GEP Endocrine Function by Autonomic Nerves}

The structural relationship between autonomic nerves and endocrine cells throughout the GEP system implies that numerous physiologically important processess are regulated by neural-hormonal interactions. However, the current understanding of these potential interactions is far from complete.

The relationship between vagal stimulation and the increase of gastrin secretion is, in fact, the only documented phenomenon demonstrating the role of autonomic nerves in the control of gastrointestinal hormones [30]. However, recent studies suggest that other peptide-containing cells of the gut may be sensitive to vagal signals. It has been shown, for example, that vagal stimulation during treatment with atropine increases, rather than decreases, gastrin secretion $[15,30]$. This observation (coupled with the recent findings that peptides such as bombesin and somatostatin affect gastrin release) has led to the suggestion that several peptide-containing cells of the gut may be influenced by parasympathetic tone $[15$, 30]. Thus it is possible that vagal signals alter the secretory rates of certain gut endocrine cells whose peptides, in turn, act as modulators - or conceivably mediators - of the gastrin response to cholinergic stimulation.

The participation of autonomic signals in the control of pancreatic islet function is now fairly well documented $[18,28,33,59,60,62,67]$. Table 2 summarizes the effects of parasympathetic and sym- 
Table 2. The autonomic control of islet function

\begin{tabular}{|c|c|c|c|}
\hline Islet hormone & $\begin{array}{l}\text { Cholinergic } \\
\text { stimulation }\end{array}$ & $\begin{array}{l}\alpha \text {-adrenergic } \\
\text { stimulation }\end{array}$ & $\begin{array}{l}\beta \text {-adrenergic } \\
\text { stimulation }\end{array}$ \\
\hline \multicolumn{4}{|l|}{ Insulin } \\
\hline Glucagon & $\hat{\uparrow}$ & $\uparrow$ or $\downarrow$ & $\uparrow$ \\
\hline Somatostatin & $\downarrow$ & $\downarrow$ & $\uparrow$ \\
\hline \multicolumn{4}{|l|}{ Pancreatic } \\
\hline polypeptide & $\uparrow$ & ! & $\uparrow$ \\
\hline
\end{tabular}

$\uparrow=$ an increase of hormone secretion, $\downarrow=$ a decrease of hormone secretion

pathetic stimulation on the secretion of hormones from each of the four major islet cell types. It is important to note that parasympathetic stimulation induces either an inhibition or a stimulation of islet hormone release; whereas, in most instances, sympathetic stimulation is capable of producing both of these effects simultaneously. These actions are due to the differing activities of the muscurinic and the alpha- and beta-adrenergic receptors (see [59, 60, 67]).

An increase of parasympathetic tone caused by either the stimulation of the vagus nerve or through the use of cholinomimetic drugs produces an increase of glucagon secretion from the A-cells and an increase of insulin secretion from the B-cells $[59,60]$. In contrast, acetylcholine decreases the release of somatostatin from the D-cells [52, 53], separating the often parallel responses of the B- and D-cells to various substrates. Although the function of pancreatic polypeptide is as yet unknown, the islet F-cells [29] seem extremely sensitive to parasympathetic signals. During a meal pancreatic polypeptide is released in a biphasic manner, and it has been suggested that the initial response is entirely related to vagal activity, with the second phase occurring due to the combined actions of intestinal hormones, circulating substrates, and vagal tone $[19,56,57]$.

Because of the generally opposing actions of the alpha- and beta-adrenergic receptors, an increase of sympathetic tone may initiate a complex dual effect. For example, catecholamines immediately inhibit the glucose-stimulated release of insulin by activation of the alpha-receptors but, over longer period of time, they increase basal insulin secretion by activation of the beta-receptors $[59,60]$. Because of this dual effect the net action of increased sympathetic tone upon B-cell function is dependent on various factors which include: the length of time sympathetic signals are provided, the presence or absence of elevated substrate levels, and the circulating levels of certain hormones capable additionally of modulating B-cell function $[59,60,67]$. An increase of sympathetic tone also elicits an increase of glucagon secretion from the A-cells, an effect usually mediated by betareceptors $[59,60]$. However, depending on the species or experimental conditions, there is evidence that the alpha-receptors may mediate either an inhibition or stimulation of glucagon release [59,60]. The administration of norepinephrine, an alphaadrenergic agonist, decreases the release of somatostatin from the D-cells $[52,53,58]$. In contrast, betaadrenergic agonists such as isoproterenol increase somatostatin release in parallel with the release of insulin and glucagon [52, 54]. Recent studies also show that alpha- and beta-receptors play a role in the regulation of F-cell function. During exerciseinduced sympathetic stimulation, pancreatic polypeptide secretion increases due to beta-receptor activation and decreases slightly if these receptors are blocked using propranolol $[2,19]$.

The actions of "peptidergic" transmitters in the regulation of islet cell function are less well known than those of the classic neurotransmitters. However, VIP reportedly induces the release of insulin, glucagon, and somatostatin $[34,55]$. Although the experimental doses of VIP used to elicit these effects are often quite high, it is possible that they are comparable to the concentration of this peptide within the islets. Other peptides not necessarily found in the islet nerves [49] also have been shown to alter A-, B-, or D-cell function. For example, substance $\mathrm{P}$ induces hyperglycemia which is thought to be mediated by the inhibition of insulin secretion and the simultaneous stimulation of glucagon release $[9,10]$. Betaendorphin, an opioid peptide, has been observed to decrease the release of somatostatin-like immunoreactive material from the canine pancreas in vitro [35]. There is also a rise of insulin and glucagon secretion which follows this effect, suggesting that beta-endorphin releases the A- and B-cells from the inhibitory actions of somatostatin. Whether the effect of substance $\mathrm{P}$ or beta-endorphin on islet function is due to a direct action upon the endocrine cells, or is mediated by intra-islet nerves is not precisely known. Further, it is unknown whether the effect of these peptides represent physiologically important mechanisms or are simply nonspecific pharmacological actions.

\section{Signal Transmission in the GEP Neuroendocrine System}

Because so many chemical messengers are present in the GEP system, it seems obvious that several different mechanisms must exist through which signal 


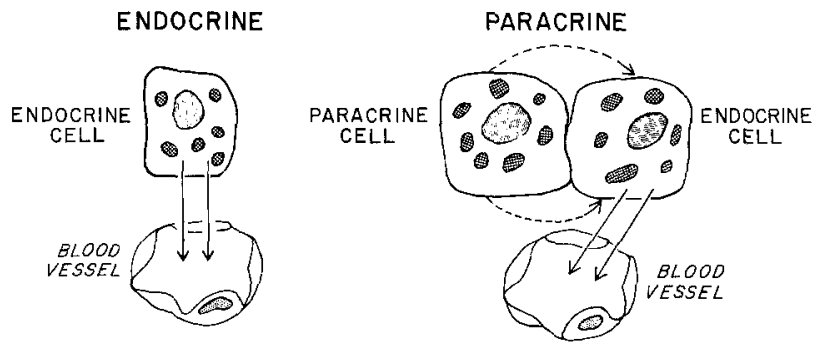

NEUROCRINE

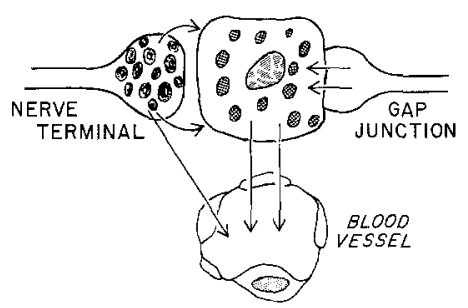

Fig. 2. Three of the four possible mechanisms through which peptides and/or amines in the GEP system may reach their target cells. See text for the explanation of each mechanism

transfer occurs in a selective and coordinated manner. In fact, there are at least three, and possibly four, major mechanisms for the transmission of these signals (Fig. 2).

Typical endocrine cells secrete hormones into the extracellular space whereupon these messengers diffuse into the blood to be carried great distances to the target cells. Gastrin, for example, must make a complete pass through the circulatory system before reaching the appropriate target cells of the gut. Since hormones contact nearly all cells of the body, selectivity is based on the presence of the appropriate receptors on the plasma membrane of target cells. Only those cells possessing receptors for a specific hormone will respond, whereas those cells lacking the specific receptors will be unaffected.

Cells having a so-called paracrine function [30, 33] also release their messengers into the extracellular space, and also rely on the presence of receptors on their target cells to ensure specificity. Because the cells affected by a paracrine signal are in the vicinity of the cell releasing the messenger, it is not necessary for a paracrine substance to diffuse into the blood. Indeed, because many cells may possess receptors for specific paracrine messengers, numerous degrading enzymes seem to have evolved to protect the distant cells from an unwanted signal should the paracrine substance find its way into the blood [33]. The importance of these degrading enzymes in the blood can be easily understood by imagining what might occur if somatostatin, a potent inhibitor of numerous processes, was to circulate in high levels throughout the body.
Another mechanism of signal transmission that has been termed neurocrine involves the release of chemical messengers from nerve terminals $[30,32]$. These signals may reach their target cells via three routes. One of these is the typical neurotransmitter route. The transmitter is released directly into the intercellular space and diffuses only a very short distance to reach receptors located on the target cell. The classic examples, of course, are acetylcholine and norepinephrine. In the case of these neurotransmitters the target cells are protected from overstimulation by the existence of degrading enzymes and/or mechanisms for the uptake of excess neural messenger. Whether a similar system exists in the case of putative neurotransmitters such as substance P, VIP, or somatostatin is not known, but seems necessary in order to prevent these peptides from interacting with cells at more distant locations. Gap-junctions offer a second route for the transfer of a neural signal to a target cell. These membrane specializations have been observed between nerve cells [27], between nerve endings and endocrine cells [43], and between endocrine cells [42]. Gap-junctions allow the passage of small molecules and/or electrical signals from one cell to another, creating a functional syncytium [59, 60]. Selectivity might involve the sensitivity of the target cell to a particular messenger, and factors such as the basic size of the pores between cells (i. e. certain molecules might be morphologically excluded from traversing some but not all gap-junctions). The third potential route for the transmission of a neural signal is identical to the classical neurosecretory mechanism (e. g. the release of oxytocin or vasopres$\sin )$. Although there is no evidence for such a mechanism in the GEP system, it seems possible that whenever peptides are released from nerves they might diffuse into the blood and could interact with specific receptors on distant target cells. Whether or not such a mechanisms is a viable means of transmitting a signal is dependent upon factors such as the absence of degrading or uptake systems mentioned above and the final dilution of the peptides actually released.

A fourth means of signal transmittal might occur through the release of peptides into the lumen of the gastrointestinal tract where they interact with "opentype" endocrine cells causing the release of a second endocrine or paracrine messenger [33]. Recent studies [63-65] indicate that gastrin, somatostatin, and substance $P$ are released into the gut lumen following nerve stimulation. While these peptides may be degraded rapidly by digestive enzymes, the interesting possibility exists that they are secreted as larger precursor molecules and actually activated by the digestive enzymes. Obviously, more research is 
needed to determine whether these substances form an important link in the transmission of signals throughout the GEP neuroendocrine system.

\section{References}

1. Baumgarten HG, Holstein AF, Owman C (1970) Auerbach's plexus of mammals and man-electron microscopical identification of three different types of neuronal processes in myenteric ganglia of the large intestine from rhesus monkeys, guinea-pig and man. Z Zellforsch 106: 376-397

2. Berger D, Floyd Jr JC, Lampman RM, Fajans SS (1980) The effect of adrenergic receptor blockade on the exercise-induced rise in pancreatic polypeptide in man. J Clin Endocrinol Metab 50: $33-39$

3. Bishop AE, Polak JM, Green IC, Bryant MG, Bloom SR (1980) The location of VIP in the pancreas of man and rat. Diabetologia 18: 73-78

4. Bloom SR (1977) Gastrointestinal hormones. Int Rev Physiol 12: 71-103

5. Bloom SR (ed) (1978) Gut hormones. Churchill Livingstone, Edinburgh London New York

6. Bloom SR, Polak JM (1978) Peptidergic versus purinergic (Letter). Lancet I: 93

7. Bodansky M, Klausner Y, Said S (1973) Biological activities of synthetic peptides corresponding to fragments of and the entire sequence of vasoactive intestinal peptide. Proc Natl Acad Sci USA 70: 382-384

8. Brinn JE, Burden HW, Schweistihal MR (1978) Innervation of the cultured fetal rat pancreas. Cell Tissue Res 182: 133-138

9. Brown M, Vale W (1976) Effects of neurotensin and substance $P$ on plasma insulin, glucagon and glucose levels. Endocrinology 98: 819-822

10. Brown M, Villarreal J, Vale W (1976) Neurotensin and substance P: effects on plasma insulin and glucagon levels. Metabolism 25 [Suppl 1]: 1459-1461

11. Burnstock G (1972) Purinergic nerves. Pharmacol Rev 24: 509-581

12. Burnstock $G$ (1979) Interactions of cholinergic, adrenergic purinergic and peptidergic neurons in the gut. In: Brooks $C$, Koizumi K, Sato A (eds) Integrative functions of the autonomic nervous system. University of Tokyo Press, Tokyo, p 145-158

13. Cheng $\mathrm{H}$, Leblond CP (1974) Origin differentiation and renewal of the four main epithelial cell types in the mouse small intestine V. Unitarian theory of the origin of the four epithial cell types. Am J Anat 141: 537-562

14. Cohen ML, Rosling E, Wiley KS, Slater IH (1978) Somatostatin inhibits adrenergic and cholinergic neurotransmission in smooth muscle. Life Sci 23: 1659-1664

15. Dockray GJ (1978) Gastrin overview. In: Bloom SR (ed) Gut hormones. Churchill Livingstone, Edinburg London New York, p 129-139

16. Elde R, Hökfelt T, Johansson D, Terenius L (1976) Immunohistochemical studies using antibodies to leucine enkephalin: Initial observations on the nervous system of the rat. Neuroscience 1: 349-351

17. Falck B (1962) Observation on the possibilities of the cellular localization of monoamines by a fluorescence method. Acta Physiol Scand [Suppl 197] 56: 1-25

18. Feldman JM (1979) Species variation in the islets of Langerhans (editorial). Diabetologia 16: 1-4

19. Floyd Jr JC (1979) Human pancreatic polypeptide. Clin Endocrinol Metab 8: 379-399
20. Fontaine J, LeLièvre C, LeDouarin NM (1977) What is the developmental fate of the neural crest cells which migrate into the pancreas of the avain embryo? Gen Comp Endocrinol 33: 394-404

21. Franco R, Costa M, Furness JB (1979) Evidence for the release of endogenous substance $\mathbf{P}$ from intestinal nerves. Nauyn-Schmiedebergs Arch Pharmacol 306: 185-201

22. Franco R, Costa M, Furness JB (1979) Evidence that axons containing substance $\mathrm{P}$ in the guinea-pig ileum are of intrinsic origin. Naunyn Schmiedebergs Arch Pharmacol 307: 57-63

23. Fujita $T$ (1959) Histological studies on the neuro-insular complex in the pancreas of some mammals. Z Zellforsch 50:30-38

24. Fujita T, Kobayashi S (1974) The cells and hormones of the GEP endocrine system. In: Fujita T (ed) Gastro-entero-pancreatic endocrine system. A cell-biological approach. Igaku Shoin, Tokyo, p 1-16

25. Furness JB, Costa M (1980) Types of nerves in the enteric nervous system. Neuroscience 5: 1-20

26. Furness JB, Costa M, Freeman CG (1979) Absence of tyrosine hydroxylase activity and dopamine $\beta$-hydroxylase immunoreactivity in intrinsic nerves of the guinea-pig ileum. Neuroscience 4: 305-310

27. Gabella $G$ (1979) Innervation of the gastrointestinal tract. Int Rev Cytol 59: 130-194

28. Gerich JE, Lorenzi M (1978) The role of the autonomic nervous system and somatostatin in the control of insulin and glucagon secretion. In: Ganong WF, Martini L (eds) Frontiers in neuroendocrinology, vol 5. Raven Press, New York, p 265-288

29. Greider MH, Gersell DJ, Gingerich RL (1978) Ultrastructural localization of pancreatic polypeptide in the F cell of the dog pancreas. J Histochem Cytochem 26: 1103-1108

30. Grossman MI (1979) Neural and hormonal regulation of gastrointestinal function: An overview. Annu Rev Physiol 41: 27-33

31. Guillemin R (1976) Somatostatin inhibits the release of acetylcholine induced electrically in the myenteric plexus. Endocrinology 99: 1653-1654

32. Häkanson R, Sundler F (1979) Peptidergic system of the gastrointestinal tract. Verh Dtsch Ges Inn Med 85: 1525-1534

33. Heitz PH (1979) The neuroendocrine system of the gastrointestinal tract. Pathol Res Pract 165: 333-348

34. Ipp E, Dobbs RE, Unger RH (1978) Vasoactive intestinal peptide stimulates pancreatic somatostatin release. FEBS Lett 90: 76-78

35. Ipp E, Dobbs R, Unger RH (1978) Morphine and $\beta$-endorphin influence the secretion of the endocrine pancreas. Nature 276: 190-191

36. Järhult J, Falck B, Ingemansson S, Nobin A (1979) The functional importance of sympathetic nerves to the liver and endocrine pancreas. Ann Surg 189: 96-100

37. Jessen KR, Polak JM, van Noorden S, Bryant MG, Bloom SR Burnstock $G$ (1979) A new approach to the demonstration of the enteric plexus origin of peptide - containing nerves by immunocytochemistry and radioimmunoassay (Abstr). Gastroenterology 76: 1161

38. Langley JN (1921) The autonomic nervous system, part 1 Heffer, London

39. Larsson L-I (1977) Ontogeny of peptide - producing nerves and endocrine cells of the gastroduodeno-pancreatic region. Histochemistry 54: 133-142

40. Lebovitz HE, Feldman JM (1973) Pancreatic biogenic amines and insulin secretion in health and disease. Fed Proc 32: 1792-1803

41. Lundquist I (1971) Insulin secretion. Its regulation by monoamines and acid amyloglucosidase. Acta Physiol Scand [Suppl] 372: $3-47$ 
42. Orci L, Malaisse-Lagae F, Ravazzola M, Rouiller D, Renold AE, Unger RH (1975) A morphological basis for intracellular communication between $\alpha$ - and $\beta$-cells in the endocrine pancreas. J Clin Invest 56: 1066-1070

43. Orci L, Perrelet A, Ravazzola M, Malaisse-Lagae F, Renold AE (1973) A specialized membrane junction between nerve endings and $\beta$-cells in the islets of Langerhans. Eur $\mathrm{J}$ Clin Invest 3: 443-445

44. Palay SL, Chan-Palay V (1975) A guide to the synaptic analysis of the neurophil. Symp Quant Biol 40: 1-16

45. Pearse AGE, Polak JM, Bloom SR (1977) The newer gut hormones. Cellular source, physiology, pathology and clinical aspects. Gastroenterology 72: 746-761

46. Pearse AGE, Takor-Takor T (1979) Embryology of the diffuse neuro-endocrine system and its relationship to the common peptides. Fed Proc 38: 2288-2294

47. Pictet RL, Rall LB, Phelps P, Rutter WJ (1976) The neural crest and the origin of the insulin-producing and other gastrointestinal hormone-producing cells. Science 191: 191-192

48. Pictet R, Rutter WJ (1972) Development of the embryonic endocrine pancreas. In: Freinkel N, Steiner DF (eds) Endocrine pancreas. Handbook of physiology, sect 7, vol 1. Williams and Wilkins, Baltimore, p 25-66

49. Powell D, Skrabanek P (1979) Brain and gut. Clin Endocrinol Metab 8: 299-312

50. Rehfeld JF (1979) Gastrointestinal hormones. Int Rev Physiol 19: 291-321

51. Said SI (1978) VIP: Overview. In: Bloom SR (ed) Gut hormones. Churchill Livingstone, Edinburgh London New York, p 465-469

52. Samols E, Weir GC (1979) Adrenergic modulation of pancreatic A, B and D cells. J Clin Invest 63: 230-238

53. Samols E, Weir GC, Ramseur R, Day JA, Patel YC (1978) Modulation of pancreatic somatostatin by adrenergic and cholinergic agonism and by hyper- and hypoglycemic sulfonamides. Metabolism 27: 1219-1221

54. Sasagawa T, Kobayashi S, Fujita T (1974) Electronmicroscope studies on the endocrine cells of the human gut and pancreas. In: Fujita $\mathrm{T}$ (ed) Gastro-entero-pancreatic endocrine system. A cell-biological approach. Igaku Shoin, Tokyo, p 17-38

55. Schebalin M, Said SI, Makhlouf GM (1977) Stimulation of insulin and glucagon secretion by vasoactive intestinal peptide. Am J Physiol 232: E197-E200
56. Schwartz TW, Holst JJ, Fahrenkrug J, Lindkaer-Jensen S, Nielsen OV, Rehfeld JF, Schaffalitzky de Muckadell OB (1978) Vagal, cholinergic regulation of pancreatic polypeptide secretion. J Clin Invest 61: 781-789

57. Schwartz TW, Rehfeld JJ (1977) Mechanism of pancreaticpolypeptide release (Letter). Lancet I: 697-698

58. Sorenson RL, Edle RP, Seybold V (1979) Effect of norepinephrine on insulin, glucagon and somatostatin secretion in isolated perifused rat islets. Diabetes 28: 899-904

59. Smith PH, Porte Jr D (1976) Neuropharmacology of the pancreatic islets. Annu Rev Pharmacol Toxicol 16: 269-285

60. Smith PH, Woods SC, Porte Jr D (1979) Control of the endocrine pancreas by the autonomic nervous system and related neural factors. In: Brooks C, Koizumi K, Sato A (eds) Integrative functions of the autonomic nervous system. University of Tokyo Press, Tokyo, p 84-97

61. Sundler F, Alumets J, Hokanson R, Fahrenkrug J, Schaffalitzky de Muckadell O (1978) Peptidergic (VIP) nerves in the pancreas. Histochemistry 55: 173-176

62. Tiscornia OM (1977) The neural control of exocrine and endocrine pancreas. Am J Gastroenterol 67: 541-560

63. Uvnäs-Wallensten K (1978) Release of substance P-like, immunoreactivity into the antral lumen of cats. Acta Physiol Scand 104: 464-468

64. Uvnäs-Wallensten K (1981) Peptides in metabolic autonomic nerves. Diabetologia [Suppl] 20: 337-342

65. Uvnäs-Wallensten K, Efendic S, Luft R (1977) Vagal release of somatostatin into the antral lumen of cats. Acta Physiol Scand 99: 126-128

66. Wood JD (1979) Neurophysiology of the enteric nervous system. In: Brooks C, Koizumi K, Sato A (eds) Integrative functions of the autonomic nervous system. University of Tokyo Press, Tokyo, p 177-193

67. Woods SC, Porte Jr D (1974) Neural control of the endocrine pancreas. Physiol Rev 54: 596-619

Dr. P. H. Smith

Department of Anatomy

Upstate Medical Center

State University of New York

766 Irving Avenue

Syracuse, NY 13210

USA

\section{Discussion after Smith's Presentation}

Kroc: What is the implication of the innervation you have described for islet grafts?

Smith: Transplanted islet tissue seems to respond appropriately to various infusions of substrates. Some investigators have administered sympathomimetic and parasympathomimetic drugs and found apparently normal responses. However, no one has reported the presence of intrinsic islet neurons in transplants; and there is a controversy as to whether or not islet transplants become reinnervated in their new locations. It probably depends upon the tissue into which they are transplanted.

Steffens: With my colleague, Dr. Strubbe, I have transplanted islets under the renal capsule of diabetic rats. We observed an abnormal response to a meal in those rats; i. e. that the cephalic insulin response, what we call the early insulin response or EIR, was absent and there was an exaggerated later or second phase of insulin after the meal. Baseline insulin and glucose levels were the same as in control rats. When the animals started to eat, glucose levels initially rose comparably in the two groups. Over time, the rise in the transplanted group became much larger than that of the controls. This suggests that during a meal, the innervation is important in attenuating the elevation of glucose in the general circulation that is caused by absorption. When we put food directly into the stomach of normal rats, bypassing the mouth, there was also no EIR and the glucose response appeared very comparable to that of the transplanted rats eating the food. Again, the suggestion is that the innervation, when triggered by oral stimuli, is very important for maintenance of glucose levels. 
Kroc: Would you expect the same results if your transplant had been into the liver? That way the insulin released would be into the portal circulation like Lacy's group does it.

Steffens: We have not done that, but perhaps Dr. Berthoud can comment.

Berthoud: We have transplanted islets into the portal beds and obtained results comparable to those of Steffens, with the exception that the later elevation of glucose in the blood is not as high.

Nicolaidis: Dr. Steffens, how do you think the innervation actually plays a role in eating? Is there only an islet effect?

Steffens: Actually, we believe there are also effects at the liver, such as Dr. Shimazu will discuss later. We think that the EIR is necessary for activation of the liver glycogen synthetase system and this thereby keeps blood glucose levels low by removing the newly absorbed glucose from the portal blood. In essence, the EIR, acting at the liver, prevents ingested glucose from attaining the general circulation. We therefore would like to suggest that the EIR is extremely important for the regulation of hepatic function but relatively unimportant in the regulation of food intake.

Smith: I would like to ask whether either Dr. Steffens or Dr. Berthoud has looked at somatostatin in the transplanted islets. McEvoy et al. (Diabetes (1978) 27: 988) have observed that transplanted islets seem to have few Dcells and this might account for some of the functional activity of transplants. It likely would alter the responsiveness of the B-cell to various inputs.

Steffens: We have not considered that.

Berthoud: We are presently measuring the content of various hormones in our transplanted animals, but the data are not yet available.

Smith: I was particularly interested in the exaggerated late rise of insulin seen by Dr. Steffens in his transplanted rats after they eat. The lack of somatostatin might lead to some sort of disinhibition of the B-cell.

B. Jeanrenaud: If one type of autonomic nerve is cut, do other types take over the function?

Smith: It's possible. Certainly, when you denervate the gut, little happens, but the correlation at the exact distribution of different neuronal types and their various functional potentials hasn't been reported. Both degeneration and regeneration probably occur in the enteric nervous system; it's very plastic.

B. Jeanrenaud: Are there differences in degeneration for different neuronal types?

Smith: I don't know of research on the topic.

Porte: There are claims that noradrenergic and cholinergic neurons come from a common precursor cell and that the local environment determines which transmitter type is made. These have all been developmental studies, but they are suggestive. The presumption has been that once a neuron develops as say an adrenergic neuron, it's an adrenergic neuron forever.

Smith: Yes, this is probably the case in the adult situation. However, there is now evidence for a considerable degree of plasticity in the autonomic nervous system (Science (1979) 206: 434). For example, if an area of the neural tube that normally gives rise to parasympathetic neurons is transplanted to an area usually forming sympathetic neurons, the nerve cells develop as part of the sympathetic system. There are also studies which show that adrenergic neurons can switch from producing norepinephrine to acetylcholine when grown under certain in vitro conditions. The plasticity of autonomic neurons seems to be related to numerous factors which include chemical substances produced by the host tissue and their relationship to other nerve cells.

Samols: The idea of an intrinsic pancreatic islet nervous system is fascinating. I wonder about the normal role of such innervation. We (J Clin Invest (1980) 65: 939) and others (N Engl J med (1979) 301: 1023) have observed cycling of the secretion of insulin and glucagon. Typically with in vivo measurements, the cycles last around ten minutes. The question, of course, arises as to whether the cycles are secondary to the release of glucose or some other nutrient by the liver or whether it might be a neural event. To test this, we have isolated the pancreas from the CNS in dogs and observed the same cycles. In fact, dog pancreas in vitro has cycles of insulin and glucagon with the same periodicity; and there are also somatostatin and PP cycles as well. When we infused epinephrine, the cycling was disrupted (Proc Endocr Soc (1979) p 74); and when we terminated the infusion, the cycling began anew (6th Intl Congr Endoc (1980) p 485; Diabetes (1980) 29: 101). It's possible that some intrinsic pancreatic nervous system such as you describe might account for this, certainly for the synchronization across the organ. Since, in our hands, no neural blocker can parmanently remove these cycles, what do you think accounts for them? Can gap junctions do this?

Smith: Your data are very interesting, and I have no answer to your questions. It's possible, of course, that some transmitter other than those you've considered is responsible. ATP or some peptide might be implicated and there are no easy blockers for these. Remember that dogs have a relatively well-innervated pancreas and that only about $10 \%$ of the nerves to the pancreas go to the exocrine pancreas, with the rest innervating the islets.

Porte: Goodner's group (Science 195: 177-179) has comparable data on cycling of islet hormones in the monkey. In their hands, there is also a small cycling of glucose levels, suggesting some sort of feedback loop. They have also found that neural blockers don't disrupt the cycles. In collaboration with them, we have also found cycles of norepinephrine levels that have the same periodicity. This suggests that the neuronal activity is somehow cycling in spite of the blockade. We have thought that VIP may be implicated since it has clearly been shown to be an intrinsic transmitter within the islets. It's possible that one neuron acts as a pacemaker of sorts; gap junctions could then 
account for the synchronous cycling among common cell types; and neurons could interconnect the various islets. Dr. Daniel Cook and I have recorded from single islet cells while simultaneously injecting electricity. He has been able to turn off an entire islet by an internal hyper-polarizing current suggesting that the electrotonic coupling is very important. Therefore, one neuron which is either connected to an extrinsic neuron or which acts as a pacemaker itself could easily control an entire islet. Lelio Orci has found an example of a gap junction between a neuron and an islet cell in the dog (Experientia (1973) 29: 1015). If this were a widespread phenomenon, traditional blockers would not be expected to have much effect on islet cycling or synchronization.

Samols: We (Stagner and Samols, in preparation) have also considered the possibility that VIP might be important. We have measured VIP and observed a cyclic activity in our isolated pancreas preparation which can be blocked with acetylcholine.

Smith: Does anyone know if there are specific blockers for VIP?

Uvnäs-Wallensten: There are none presently available.

Porte: Is VIP only in neurons or is it also found within endocrine cells?

Uvnäs-Wallensten: Most people (5 out of 6 papers in the literature) agree that VIP is found only in neurons and not in endocrine cells.

Porte: So the reports that cholinergic stimulation causes increased VIP release from peripheral tissues would imply that the effect is at an autonomic ganglion?

Uvnäs-Wallensten: Not necessarily, since receptors for acetylcholine might be located anywhere along an axon and activation at any point might therefore influence VIP release.

Shimazu: Dr. Smith, have you looked at nerve terminals in the liver?
Smith: No, but the innervation of the liver is controversial. Some people have reported that both cholinergic and noradrenergic neurons innervate the hepatocytes, whereas others report only cholinergic innervation. This may well represent a species variation (Woods et al., In: Brownlee M (ed) Handbook of diabetes mellitus, vol. 3, Garland, New York, 1981).

Novin: How do electrical activity and insulin secretion relate?

Porte: The cycling of electrical activity of B-cells depends upon the amount of glucose present, as does the insulin secretion, but these are different than the cycles of hormone levels reported by Dr. Samols. Those presumably represent cycling of the entire organ.

Samols: Yes, and as the glucose levels change, we see the same periodicity of hormone levels, but with peaks of different amplitude.

Porte: And just to confuse the area a little bit more, Illani Atwater claims that she has observed very rapid oscillations of insulin secretion corresponding to the cycling of electrical activity of individual islets (Proc Physiol Soc (1979) 57: 16-17). So there may be two kinds of cycling. One is related to electrical plateau potentials and occurs within individual islets, whereas a second is related to the entire organ.

Nicolaidis: We found many years ago that if you stimulate the tongue, you can induce oscillations of glucose levels in the blood with 7 -minute periods.

Samols: That's interesting; however, in our experiments, the glucose levels cannot be accounting for the oscillations of hormone secretion since we keep the levels of glucose constant.

Porte: Yes, but when we clamp insulin and glucagon levels, we see large cycles of glucose levels in vivo, so there are many interactions occurring. 